\title{
Characterization of Additives Typically Employed in EPDM Formulations by Using FT-IR of Gaseous Pyrolyzates
}

\author{
Natália Beck Sanches \\ Instituto Tecnológico de Aeronáutica - ITA \\ Silvana Navarro Cassu \\ Instituto Tecnológico de Aeronáutica - ITA \\ Divisão de Química - AQI, Instituto de Aeronáutica e Espaço - IAE \\ Milton Faria Diniz \\ Divisão de Química - AQI \\ Instituto de Aeronáutica e Espaço - IAE \\ Rita de Cássia Lazzarini Dutra \\ Instituto Tecnológico de Aeronáutica - ITA \\ Divisão de Química - AQI, Instituto de Aeronáutica e Espaço - IAE
}

\begin{abstract}
In this study, Fourier transform infrared spectroscopy (FT-IR) was employed to investigate the gaseous pyrolysis products of ethylene-propylene-diene rubber (EPDM). The objective was to evaluate the potential of FT-IR analysis of gaseous pyrolyzates (PY-G/FT-IR) for characterization of EPDM additives. Two EPDM formulations, containing additives typically employed in EPDM rubbers, were analyzed. Initially, gaseous pyrolysis products from paraffin oil, stearic acid, 2,2,4-trimethyl-1,2-dihydroquinoline, tetramethylthiuram monosulfide (TMTM), tetramethylthiuram disulfide (TMTD), and 2-mercaptobenzothiazole (MBT) were characterized separately, and their main absorptions were identified. Subsequently, the gaseous pyrolysis products of raw, unvulcanized, and vulcanized EPDM formulations were analyzed. The similarities observed in the FT-IR spectra of unvulcanized and vulcanized EPDM show that the vulcanization process does not interfere with the pyrolysis products. The identification of the functional groups of the studied additives was possible in both unvulcanized and vulcanized EPDM samples, without solvent extraction. Results also demonstrate that the PY-G/FT-IR technique can identify additives containing sulfur in concentrations as low as $1.4 \mathrm{phr}(1.26 \%)$ in both unvulcanized and vulcanized EPDM. However, the method showed some limitation due to overlapping and to similarities of TMTM and TMTD PY-G/FT-IR spectra, which could not be distinguished from each other. The PY-G/FT-IR technique is a faster and cheaper alternative to the sophisticated techniques usually applied to detection of additives in rubbers.
\end{abstract}

Keywords: EPDM, gaseous pyrolyzates, additives, characterization, FT-IR.

\section{Introduction}

The detection of polymeric additives is a matter of great relevance because it enables the reconstruction of formulations in unknown rubbers, the solving of manufacturing problems, the investigation of a competitor's compounds and the realization of quality studies ${ }^{[1]}$.

Low molecular weight chemical compounds, known as additives, are incorporated in to rubbers to obtain desirable properties ${ }^{[2]}$. The main additives used in rubbers are antioxidants, vulcanizing agents, accelerators, reinforcing agents, activators, and processing aids. Many kinds of compounds can be employed to perform the same function. For example, dithiocarbamates, benzothiazoles, amines, thioureas, and thiuram disulfides can all act as accelerators ${ }^{[3]}$. Additives are selected based on the rubber vulcanization system and intended final properties.
Additive analysis can be challenging because of the complex and tedious process of isolating additives from compounded rubber ${ }^{[4]}$. Some methods require solvent extraction, which may cause chemicals changes and interferences between the solvent and additives. This should be taken into consideration when choosing analytical methodology for additive determination. Hence, the use of techniques that allow for analysis of additives without prior separation from the polymer is always preferred.

There are many sample preparation techniques suitable for studying polymers. The pyrolysis technique, which consists of decomposing the molecule into volatile fragments via thermal energy, has been extensively used $^{[5]}$. It can be applied to study polymers by assessing their thermal behavior or by studying the pyrolysis products. 
The analysis of pyrolysis products can clarify the composition of a polymer, because the obtained fragments are related to the fundamental structure of the original macromolecule.

Several studies have been published about polymer and additive analysis using the pyrolysis technique ${ }^{[5-10]}$. Typically, the analytical techniques used to identify the fragments from pyrolysis are gas chromatography (GC) and mass spectrometry (MS). The coupling of these techniques has been applied for many years in the characterization of organic compounds $\mathrm{s}^{[6,11-16]}$.

Among the various additives used in a rubber system, the analysis of sulfur compounds can be particularly complex. More than one method is typically employed and the results are correlated, because no single technique can provide a complete evaluation of these compounds. Some of the methods used to identify accelerators and antioxidants containing sulfur compounds are GC/MS, thermal desorption (TD)-GC/MS, high-performance liquid chromatography, and thin-layer chromatography. Generally, these methods require solvent extraction of the additives and are time-consuming ${ }^{[17]}$.

In the literature, only a few studies have employed Fourier transform infrared analysis of gaseous pyrolyzates (PY-G/FT-IR) for rubber characterization. Nunes et al. [18] compared the results of a tracking resistance test and PY-G/FT-IR analysis to study the degradation mechanisms of EPDM rubber. They identified ethene, methane, $\mathrm{CO}$, and $\mathrm{CO}_{2}$ as the products of EPDM pyrolysis. Matheson et al. ${ }^{[19]}$ used PY-G/FT-IR to determine the polymer content in carbon-filled natural rubber (NR) and styrene-butadiene rubber (SBR). They concluded that NR/SBR rubbers can be analyzed by PY-G/FT-IR with no interference from the carbon black load up to $35 \%$. Fernández-Berridi et al. ${ }^{[20]}$ used PY-G/FT-IR and highresolution thermogravimetric analysis (Hi-Res TGA) to determine the elastomer content of SBR/NR in used tires. Both techniques were found to be adequate for performing compositional analysis of vulcanizates, but Hi-Res TGA was unable to determine the relative content of styrene and butadiene in the SBR samples. Even though the PY-G/FT-IR technique was used, none of the cited studies applied infrared spectroscopy to detect additives in gaseous products after rubber pyrolysis.

In a previous work ${ }^{[21]}$, PY-G/FT-IR was applied to investigate vulcanized elastomers with additives that had been previously extracted with solvents. Several rubbers and rubber blends were identified from the gaseous products yielded during pyrolysis. The aim of that study was to identify the polymeric matrix.

The present study focused on the detection of additives in EPDM rubber by PY-G/FT-IR, without prior extraction. FT-IR spectra of raw, unvulcanized, and vulcanized EPDM can provide different and complementary information; therefore their PY-G/FT-IR spectra were also assessed. Raw rubber was analyzed as a reference sample, and its FT-IR spectrum was compared to the spectra of unvulcanized and vulcanized EPDM to distinguish polymer-only absorptions. Unvulcanized rubber was analyzed to obtain the spectra prior to the vulcanization process, when additives are supposed to be chemically preserved. Qualitative analysis was performed, focusing only on the detection or not of the additives bands.

\section{Experimental}

\section{Materials}

The additives paraffin oil, stearic acid, 2,2,4-trimethyl1,2-dihydroquinoline (TMQ), tetramethylthiuram monosulfide (TMTM), and 2-mercaptobenzothiazole (MBT) were characterized individually as received.

Commercial grade EPDM Keltan 21, containing the diene ENB (ethylidene norbornene), from DSM Elastômeros do Brasil Ltda, Brazil, was used in this study as received, without additives (raw rubber). The neat rubber was used as a reference sample.

Unvulcanized and vulcanized samples (sample terminology is in accordance with the ASTM D1566$11^{[22]}$ ) were prepared using EPDM Keltan 21 and rubber grade chemicals, according to compositions $\mathrm{A}$ and $\mathrm{B}$ shown in Table 1. Composition B follows formula No. 1 from the Standard ASTM D3568-03 ${ }^{[23]}$, which applies to

Table 1. Composition of EPDM rubber.

\begin{tabular}{|c|c|c|}
\hline Component & $\begin{array}{c}\text { SAMPLE A } \\
\text { Unvulcanized and } \\
\text { Vulcanized }\left(\mathbf{p h r}^{a}\right)\end{array}$ & $\begin{array}{c}\text { SAMPLE B } \\
\text { Unvulcanized and } \\
\text { Vulcanized }\left(\mathrm{phr}^{a}\right)\end{array}$ \\
\hline EPDM Keltan 21 & 100 & 100 \\
\hline Paraffin oil & 1.0 & 50.0 \\
\hline Stearic acid & 0.5 & 1.0 \\
\hline TMQ & 1.0 & 0 \\
\hline TMTM & 0.7 & 0 \\
\hline TMTD & 0 & 1.0 \\
\hline MBT & 0.7 & 0.5 \\
\hline $\mathrm{ZnO}$ (Zinc oxide) & 2.0 & 5.0 \\
\hline Carbon black & 5.0 & 80.0 \\
\hline S (Sulfur) & 0.7 & 1.5 \\
\hline
\end{tabular}

${ }^{a}$ parts per hundred parts of rubber.

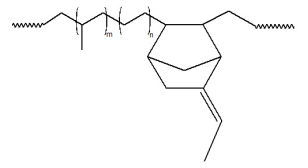

(i) EPDM<smiles>CC1=CC(C)(C)Nc2ccccc21</smiles>

(iii) TMQ<smiles>CN(C)C(=S)SSC(=S)N(C)C</smiles>

(v) TMTD

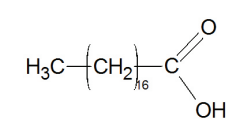

(ii) Stearic Acid<smiles>CN(C)C(=S)SC(=S)N(C)C</smiles>

(iv) TMTM

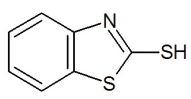

(vi) MBT
Figure 1. Molecular structure of the analyzed compounds prior to pyrolysis. 
general purpose EPDM types. The molecules of the compounds prior to pyrolysis are shown in Figure 1.

\section{Pyrolysis}

Each additive was weighed as received, placed in a pyrolysis tube, and pyrolyzed individually with a Bunsen burner. The gas that evolved was trapped in a preheated gas cell, as described in a previous study ${ }^{[21]}$ and directly analyzed by FT-IR.

Raw, unvulcanized, and vulcanized EPDM were cut into small pieces and pyrolyzed separately, as described above. The gaseous pyrolyzates were analyzed by FT-IR

\section{Infrared spectroscopy}

FT-IR was carried out with a PerkinElmer Spectrum One spectrometer. Spectra were collected with $4 \mathrm{~cm}^{-1}$ resolution and an average of 20 scans over the wavenumber range $4000-500 \mathrm{~cm}^{-1}$ in transmission mode.

\section{Results and Discussion}

Pyrolysis is a valuable sample preparation technique that yields complex and rich information. Depending on the substance and pyrolysis conditions, the result may contain gaseous, liquid, and solid products. In this work, only the gaseous phase was analyzed by FT-IR, which is a powerful tool for identification and characterization of gaseous pyrolysis products ${ }^{[24]}$. Peaks observed in the FT-IR spectrum differ depending on the physical state of the molecule. The changes in the band shape and peak shifts may occur because of fewer intermolecular interactions in the gas phase than liquid or solid phases ${ }^{[25,26]}$.

Generally, an exact identification of all the detected bands is neither possible nor necessary. A more productive approach is to search for evidence of the presence or absence of characteristic functional groups ${ }^{[24,25,27]}$. In this

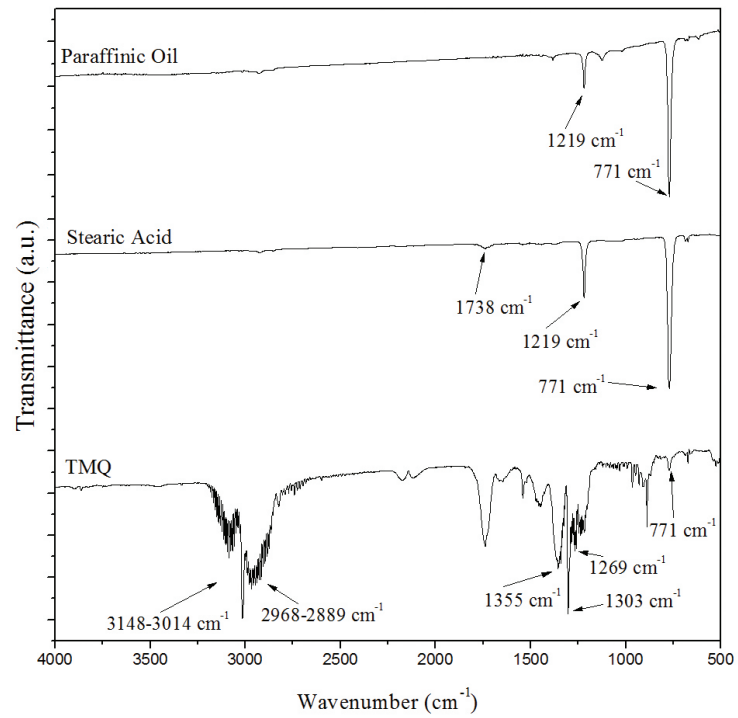

(a) study, this practice was used for the assignment of peaks in the PY-G/FT-IR spectra.

\section{Infrared analysis of additives}

The final properties of rubber are determined by additives. Therefore, it is essential to characterize all additives prior to mixing them into the rubber compound to ensure the right compounds are being employed. For this reason, paraffin oil, stearic acid, TMQ, TMTM, TMTD, and MBT additives were analyzed separately by PY-G/FT-IR. The FT-IR spectra of the gaseous pyrolysis products are shown in Figure 2. Spectra of additives in the original state are available on the BIO-RAD/SADTLER Reference Database ${ }^{[28]}$.

The main bands observed in the FT-IR spectrum of the gaseous pyrolysis products from paraffin oil are 1219 and $771 \mathrm{~cm}^{-1}$ (Figure 2a). The band observed at $1219 \mathrm{~cm}^{-1}$ can be attributed to the $\mathrm{CH}_{3}$ group. The band at $771 \mathrm{~cm}^{-1}$ can be attributed to the $\mathrm{CH}_{2}$ group and/or $\mathrm{CH}$ aromatic group ${ }^{[27]}$. However, paraffin oil does not contain any aromatic groups, but rubber grade paraffin oils are mixtures of paraffin oil (50\%-68\%), naphthenic oil (26\%-40\%), and aromatic oil (2\%-7\%). Hence, $\mathrm{C}=\mathrm{C}$ and $\mathrm{C}-\mathrm{H}$ of the aromatic groups and the $\mathrm{CH}_{2}$ and $\mathrm{CH}_{3}$ groups would be present in rubber grade paraffin oils. The absorption that can be attributed to aromatic groups is verified at $771 \mathrm{~cm}^{-1}$.

The FT-IR spectrum of stearic acid's gaseous pyrolysis products is shown in Figure 2a. The band at $771 \mathrm{~cm}^{-1}$, the peak at $1738 \mathrm{~cm}^{-1}$, and the band at $1219 \mathrm{~cm}^{-1}$ is attributed to the $\mathrm{CH}_{2}, \mathrm{C}=\mathrm{O}$, and $\mathrm{C}-\mathrm{O}$ group, respectively ${ }^{[26]}$.

The FT-IR spectrum of the gaseous pyrolysis products of the antioxidant TMQ is presented in Figure 2a. The band at $1303 \mathrm{~cm}^{-1}$ can be attributed either to the $\mathrm{N}-\mathrm{H}$ group $^{[25]}$ or/and to the $\mathrm{C}-\mathrm{N}$ group ${ }^{[27]}$. The peaks in the regions of $3148-3014 \mathrm{~cm}^{-1}$ and $771 \mathrm{~cm}^{-1}$ are attributed to $\mathrm{C}-\mathrm{H}$ aromatic groups or/and $\mathrm{N}-\mathrm{H}^{[25]}$. The bands at

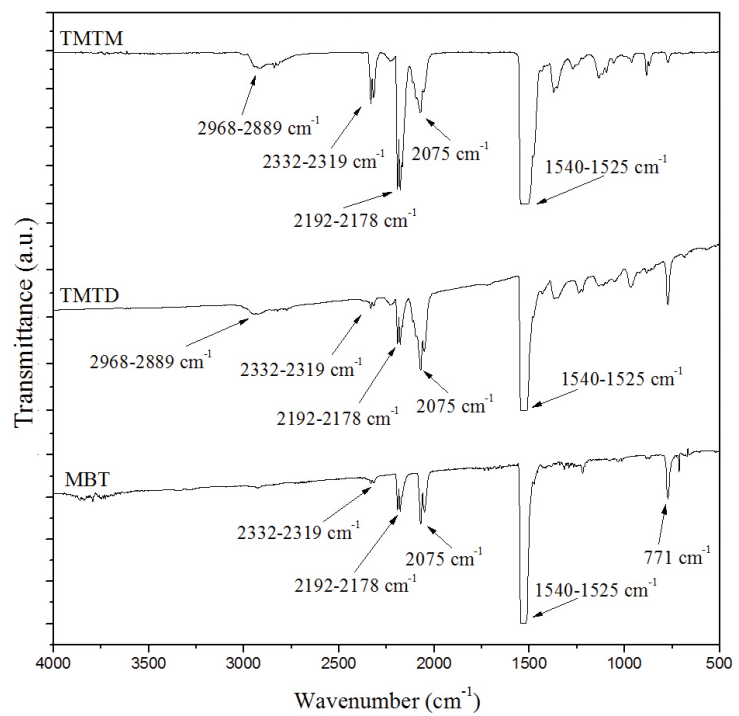

(b)

Figure 2. PY-G/FT-IR spectra of (a) additives without sulfur; and (b) additives containing sulfur. 
$2968-2889 \mathrm{~cm}^{-1}$ and $1355 \mathrm{~cm}^{-1}$ are typical of $\mathrm{CH}_{3}$ groups, and the peak at $1269 \mathrm{~cm}^{-1}$ is attributed to $\mathrm{C}-\mathrm{N}$ aromatic group.

During pyrolysis of TMQ, it is possible that cleavage of the hydrogen-nitrogen bond and the $\mathrm{C}-\mathrm{CH}_{3}$ groups occurs. The aromatic rings presumably are stable because of resonance. The main degradation products of TMQ determined in the literature ${ }^{[29]}$ are as follows: $\mathrm{p}, \mathrm{p}^{\prime}-$ diamino-2,2-diphenylpropane, methyl, and small quantities of aniline, whose chemical structures contain groups that can be related to the absorptions observed in the TMQ spectrum (Figure 2a).

Figure $2 \mathrm{~b}$ shows the FT-IR spectrum of the gaseous pyrolysis products of sulfur compounds. TMTM spectrum shows bands at $2968-2889 \mathrm{~cm}^{-1}$, which are attributed to the $\mathrm{CH}_{3}$ group. The band at $2075 \mathrm{~cm}^{-1}$ can be probably attributed to the $\mathrm{N}=\mathrm{C}=\mathrm{S}$ (isothiocyanate) group ${ }^{[27]}$.

Spectra of $\mathrm{CS}_{2}$ in the gaseous state, obtained from reference databases ${ }^{[28,30]}$, show absorptions at 2320, 2180 , and $1530 \mathrm{~cm}^{-1}$, which are similar to absorptions at 2332-2319, 2192-2178, and 1540-1525 $\mathrm{cm}^{-1}$ detected in the PY-G/FT-IR spectrum of TMTM. Hence, $\mathrm{CS}_{2}$ is a pyrolysis product of this additive. These absorptions can also be attributed to the presence of the $\mathrm{C}=\mathrm{S}$ group.

Figure $2 \mathrm{~b}$ also shows the FT-IR spectrum for the gaseous pyrolysis products of TMTD, which present absorptions similar to TMTM. These results were expected because the two molecules have similar structures. The TMTD molecule has two atoms of sulfur while TMTM has only one. The S-S bond of TMTD was not detected in the FT-IR spectrum, probably because its vibration is very weak ${ }^{[27]}$. According to Nieuwenhuizen ${ }^{[31]}$, TMTD decomposes by heat into TMTU (1,1,3,3-tetramethylthiourea), $\mathrm{CS}_{2}$, and sulfur. Considering that the element sulfur is the only pyrolysis product of TMTD that is different from TMTM and that atomic sulfur is not detectable by infrared, it was expected that the TMTD spectrum would have the same bands as the TMTM spectrum.

The last additive analyzed was the MBT accelerator. According to Contini et al. ${ }^{[32]}$, MBT exists in its tautomeric thione (benzothiazoline-2-thione) form in the vapor phase. The thione form has a $\mathrm{C}=\mathrm{S}$ bond and a hydrogen atom bonded to the nitrogen instead of the sulfur and endocyclic $\mathrm{C}=\mathrm{N}$ bond (thiol form). According

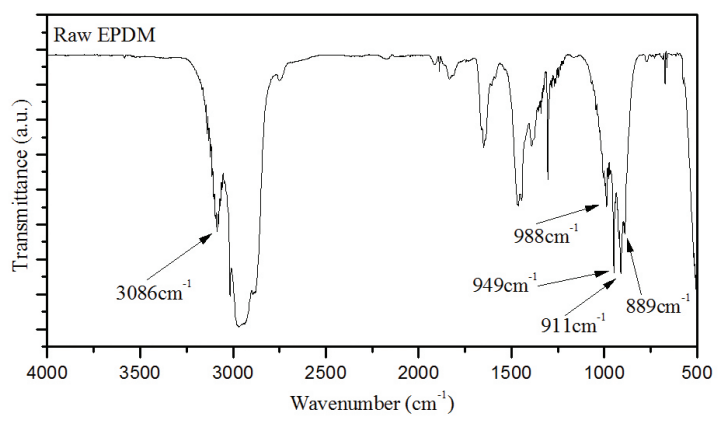

(a)

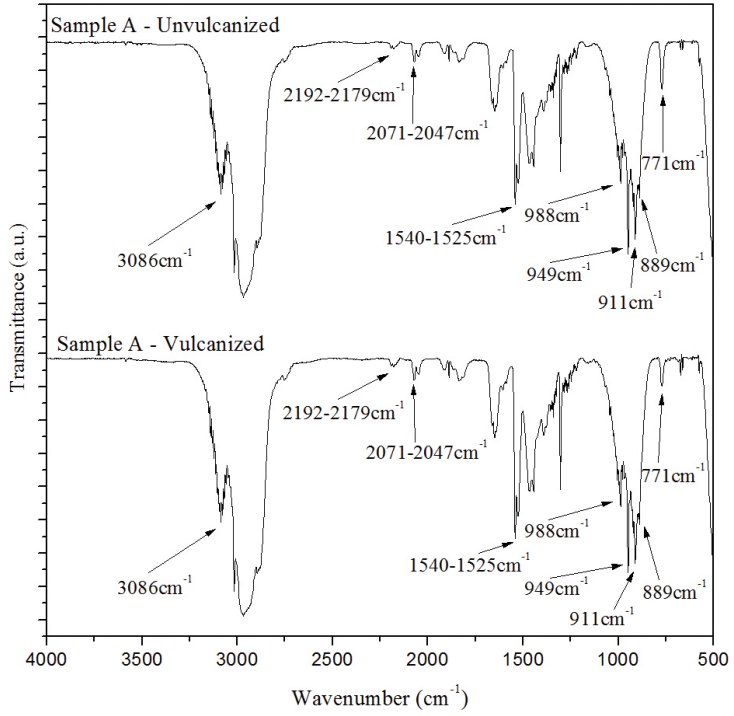

(b)

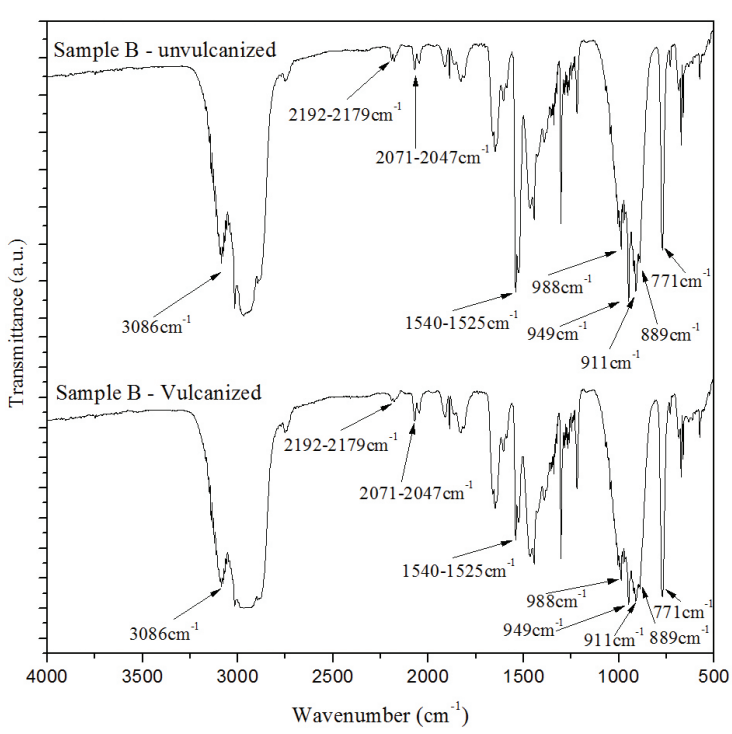

(c)

Figure 3. PY-G/FT-IR spectra of EPDM. (a) raw, (b) Sample A - unvulcanized and vulcanized, and (c) Sample B - unvulcanized and vulcanized. 
to $\mathrm{Wu}$ et al. ${ }^{[33]}$ and Mohamed et al. ${ }^{[34]}$, thione is also the dominant form in the solid state.

The FT-IR spectrum for the gaseous pyrolysis products of MBT is presented in Figure 2b. The peak at $771 \mathrm{~cm}^{-1}$ is attributed to the $\mathrm{C}-\mathrm{H}$ aromatic group.

The spectrum of MBT, like the spectrum of TMTM, shows a strong doublet at 1540-1525 $\mathrm{cm}^{-1}$. Weak doublets were also detected at $2332-2319 \mathrm{~cm}^{-1}$ and 2192-2178 $\mathrm{cm}^{-1}$. All three doublets can be assigned to $\mathrm{CS}_{2}$ and/or the $\mathrm{C}=\mathrm{S}$ group analogous to the TMTM assignment. This assignment is associated with the thione form cited by Contini ${ }^{[32]}$.

Taking the assignments of the additives spectra into consideration, all the additives can be differentiated from each other using the FT-IR spectra of gaseous pyrolyzates, except the TMTM and TMTD thiuram accelerators. Moreover, the additives containing sulfur are easily distinguished from the others by detection of doublets in the regions 2332-2319, 2192-2178, and 1540-1525 $\mathrm{cm}^{-1}$. This can be very helpful in the investigation of an unknown rubber, because the PY-G/FT-IR technique can readily indicate whether or not a sulfur compound was incorporated in the rubber.

\section{Infrared analysis of EPDM samples}

The FT-IR spectra of the gaseous pyrolysis products of raw, unvulcanized, and vulcanized EPDM are shown in Figure 3. The absorptions detected in the gaseous pyrolyzates of the raw EPDM FT-IR spectrum are related exclusively to the EPDM chain, because no additives were added to this sample. The peak at $3086 \mathrm{~cm}^{-1}$ is attributed to the $\mathrm{C}-\mathrm{H}$ olefinic and/or aromatic. The peaks at 988 and $911 \mathrm{~cm}^{-1}$ were attributed to the $\mathrm{C}=\mathrm{C}$ vinyl group. The band around $949 \mathrm{~cm}^{-1}$ was attributed to $\mathrm{C}=\mathrm{C}$ trans bonds. The bands observed at $889 \mathrm{~cm}^{-1}$ and at $1385 \mathrm{~cm}^{-1}$ were attributed to the $\mathrm{RR}^{\prime} \mathrm{CCH}_{2}$ group and to the $\mathrm{CH}_{3}$ group, respectively. The assignments are in accordance with a published study ${ }^{[6]}$, which evaluated the ENB content in EPDM rubber by PY-GC/MS. These results indicate a mix of alkanes and alkenes among the major pyrolysis products of EPDM rubber.

Additionally, spectra of unvulcanized and vulcanized EPDM (Figures 3b, c) showed doublets around 2192-2179, 2071-2047, and 1540-1525 $\mathrm{cm}^{-1}$, and a band at $771 \mathrm{~cm}^{-1}$. These peaks were absent in the PY-G/FT-IR spectrum of the raw EPDM (Figure 3a) and thus are related to the additives.

To evaluate the main absorptions from the additives in the FT-IR spectra and to establish their connection to the bands observed in the PY-G/FT-IR spectra of unvulcanized and vulcanized EPDM, the most important FT-IR absorptions are summarized in Table 2. Band intensities are indicated as follows: $S$ for strong, $M$ for medium, and $W$ for weak.

As can be seen in Table 2, none of the peaks detected in the PY-G/FT-IR spectra of the additives were seen in the PY-G/FT-IR spectrum of raw EPDM, as expected. Unvulcanized and vulcanized samples have similar absorption bands. The doublets in the region of $2192-2178 \mathrm{~cm}^{-1}$ and $1540-1525 \mathrm{~cm}^{-1}$ can be attributed to the additives TMTM, TMTD, and MBT, all containing sulfur in their molecular structure. The peak in the region of $771 \mathrm{~cm}^{-1}$ can be associated with all of the analyzed additives.

Modifications occurring during the vulcanization reaction can make detection of additives in rubbers very difficult. The additives can be chemically altered with heat and simultaneous reactions. In theory, results obtained from the same rubber can be different before and after vulcanization. Nevertheless, these differences were not observed in this study as the PY-G/FT-IR spectra of unvulcanized and vulcanized rubber were similar.

Usually, infrared absorption of sulfur compounds in solid and liquid state is weak ${ }^{[31]}$. Generally, it is necessary to use complementary techniques, such as Raman spectroscopy, to detect them. In this study, as the gaseous pyrolyzate was analyzed, the absorptions related to the sulfur compound in the gaseous state showed stronger intensity. PY-G/FT-IR detected concentrations of MBT and TMTM or TMTD as low as $1.4 \mathrm{phr}(1.26 \%)$, confirming the potential of this technique to be applied for detection of sulfur compounds. Even the spectrum of vulcanized EPDM, whose additives are supposed to be largely consumed in the crosslinking process, showed strong bands in the gaseous pyrolyzate that were attributed to sulfur compounds.

Table 2. Bands in the PY-G/FT-IR spectra of EPDM rubbers related to the additives.

\begin{tabular}{llcccc}
\hline \multicolumn{1}{c}{ EPDM Sample } & \multicolumn{5}{c}{ Wavenumber $\left(\mathbf{c m}^{-1}\right)$} \\
\hline Raw EPDM & & - & - & - & - \\
\hline Sample A & Unvulcanized & $2192-2179(W)$ & $2071-2047(W)$ & $1540-1525(S)$ & $771(W)$ \\
& Vulcanized & $2192-2179(W)$ & $2071-2047(W)$ & $1540-1525(S)$ & $771(W)$ \\
\hline Sample B & Unvulcanized & $2192-2179(W)$ & $2071-2047(W)$ & $1541-1527(S)$ & $772(W)$ \\
& Vulcanized & $2192-2179(W)$ & $2071-2047(W)$ & $1541-1526(S)$ & $772(W)$ \\
\hline Paraffin Oil & & - & - & - & $771(M)$ \\
TMQ & & - & - & - & $771(W)$ \\
Stearic Acid & & - & - & $750(S)$ \\
TMTM & & $2192-2178(S)$ & $2075(M)$ & $1540-1525(S)$ & $771(W)$ \\
TMTD & & $2192-2178(S)$ & $2070-2052(M)$ & $1546-1525(S)$ & $771(W)$ \\
MBT & & $2192-2178(W)$ & $2071-2051(W)$ & $1540-1525(S)$ & $771(W)$ \\
\hline
\end{tabular}


Table 3. Components and pyrolysis products from the literature and functional groups assigned in this study.

\begin{tabular}{|c|c|c|}
\hline Component & $\begin{array}{l}\text { Pyrolysis Products } \\
\text { (from literature) }\end{array}$ & $\begin{array}{l}\text { Functional Groups assigned in } \\
\text { this study by PY-G/FT-IR }\end{array}$ \\
\hline EPDM & $\begin{array}{l}\text { Propylene, propane, butane, 1-hexene, 1-heptene, } \\
\text { benzene, toluene, 4-ethylidene-1-cyclopentene, and } \\
\text { 3-ethylidene-1-cyclopentene }{ }^{[6]}\end{array}$ & $\begin{array}{c}\mathrm{C}=\mathrm{C} \text { vinyl } \\
\mathrm{C}=\mathrm{C} \text { trans } \\
\mathrm{RR}^{\prime} \mathrm{CCH}_{2} \\
\mathrm{CH}_{3} \\
\mathrm{C}-\mathrm{H} \text { olefinic and/or aromatic }\end{array}$ \\
\hline Paraffin Oil & Hydrocarbon chains from $\mathrm{C}_{20}$ to $\mathrm{C}_{34}{ }^{[8]}$. & $\begin{array}{c}\mathrm{CH}_{3} \\
\mathrm{CH}_{2} \text { and/or C-H aromatic }\end{array}$ \\
\hline Stearic Acid & $\begin{array}{c}\text { Alkenes from } \mathrm{C}_{3} \text { to } \mathrm{C}_{17} \text { and large amount of vaporized } \\
\text { stearic acid }{ }^{[8]}\end{array}$ & $\begin{array}{l}\mathrm{CH}_{2} \\
\mathrm{C}=\mathrm{O} \\
\mathrm{C}-\mathrm{O}\end{array}$ \\
\hline TMQ & $\begin{array}{c}\text { Aniline, methyl, TMQ, } \\
\text { p,p'-diamino-2,2-diphenylpropane }^{[29]}\end{array}$ & $\begin{array}{c}\mathrm{N}-\mathrm{H} \\
\mathrm{C}-\mathrm{H} \text { aromatic } \\
\mathrm{C}-\mathrm{N} \\
\mathrm{CH}_{3} \\
\mathrm{C}-\mathrm{N} \text { aromatic }\end{array}$ \\
\hline TMTM & TMTU, $\mathrm{CS}_{2}^{[31]}$ & $\begin{array}{c}\mathrm{CS}_{2} \text { and } / \text { or } \mathrm{C}=\mathrm{S} \\
\mathrm{CH}_{3} \\
\mathrm{~N}=\mathrm{C}=\mathrm{S}\end{array}$ \\
\hline TMTD & TMTU, $\mathrm{CS}_{2}$, sulfur ${ }^{[31]}$ & $\begin{array}{c}\mathrm{CS}_{2} \text { and } / \text { or } \mathrm{C}=\mathrm{S} \\
\mathrm{CH}_{3} \\
\mathrm{~N}=\mathrm{C}=\mathrm{S}\end{array}$ \\
\hline MBT & Benzothiazoline-2-thione $27^{[33]}$ & $\begin{array}{l}\mathrm{CS}_{2} \text { and/or } \mathrm{C}=\mathrm{S} \\
\mathrm{C}-\mathrm{H} \text { aromatic }\end{array}$ \\
\hline
\end{tabular}

Table 3 shows the association of the pyrolysis products found in the literature with the functional groups assigned in this study for each of the compounds analyzed.

In Table 3, the referenced studies usually employed PY/GC and/or PY/GC/MS techniques to determine the degradation products. These techniques have the merit of performing separation of the decomposition products prior to their identification. In this study, even though the employed PY-G/FT-IR technique does not separate the evolving pyrolyzates, identification of the functional groups in the EPDM samples was possible. Furthermore, by correlating the data presented for each compound in Table 3, it is evident that the functional groups assigned by PY-G/FT-IR are related to the pyrolysis products in the literature.

The technique PY-G/FT-IR used in this study is faster and cheaper than other techniques because pyrolysis was performed using a Bunsen burner without additive extraction. Moreover, FT-IR is a more affordable technique than GC and/or MS techniques. A laboratory without sophisticated equipment can take advantage of this simple, rapid, and inexpensive technique, as an alternative option, to characterize and develop compounds, reconstruct formulations, and perform quality control.

\section{Conclusion}

The characterization of additives frequently used in EPDM rubber was performed using the PY-G/FT-IR technique, which was capable of distinguishing all the additives from each other, except the TMTM and TMTD thiuram accelerators, which presented similar FT-IR spectra. Moreover, these sulfur additives showed characteristic absorptions enabling their differentiation from additives without sulfur.

The PY-G/FT-IR technique was applied to the study of unvulcanized and vulcanized EPDM samples. The technique was able to detect absorptions of sulfur additives present in EPDM rubber in concentrations as low as $1.4 \mathrm{phr}(1.26 \%)$, even in vulcanized samples. The characteristic groups of all studied additives were identified in unvulcanized and vulcanized EPDM, even without their previous extraction using solvents. Some limitations in the method were observed because of the absorbance band overlap.

The PY-G/FT-IR technique used in this study is less time-consuming and expensive than other techniques applied for the investigation of rubber compounding, and it can be employed for the analysis of separate additives, neat rubber (raw), and unvulcanized and vulcanized compounds.

These findings are valid for the studied formulations. Further investigation would be necessary to verify whether the methodology is suitable for others rubbers and additives formulations. 


\section{References}

1. Raemaekers, K. G. H. \& Bart, J. C. J. - Thermoch. Acta, 295, p.1 (1997). http://dx.doi.org/10.1016/S00406031(97)00097-X

2. Çavdar, S.; Özdemir, T. \& Usanmaz, A. - Plast. Rubber Compos., 39, p.277 (2010). http://dx.doi.org/10.1179/174 $328910 X 12647080902970$

3. Fishbein, L. - Scand J Work Environ Health, 9, p.7 (1983). PMid:6356341.

4. Buchberger, W. \& Stftinger, M. - Adv. Polym. Sci., 248, p.39 (2012). http://dx.doi.org/10.1007/12_2011_147

5. Wampler, T. P. - "Applied Pyrolysis Handbook", CRC Press, Boca Raton (2007).

6. Choi, S. \& Kim, Y. - Polym. Test., 30, p.509 (2011). http:// dx.doi.org/10.1016/j.polymertesting.2011.04.005

7. Hiltz, J. A. - J. Appl. Pyrolysis, 55, p.135 (2000). http:// dx.doi.org/10.1016/S0165-2370(99)00090-X

8. Wang, F. C. \& Buzanowski, W. C. - J. Chromatogr. A, 891, p.313 (2000). http://dx.doi.org/10.1016/S00219673(00)00648-8

9. Jansson, K. D.; Zawodny, C. P. \& Wampler, T. P. - J. Appl. Pyrolysis, 79, p.353 (2007). http://dx.doi.org/10.1016/j. jaap.2006.12.009

10. Kusch, P. - Spectroscopy (2012).

11. Sobeih, K. L.; Baron, M. \& Gonzales-Rodriguez, J. - J. Chromatogr. A, 1186, p.51 (2008). PMid:17980891. http:// dx.doi.org/10.1016/j.chroma.2007.10.017

12. Kim, S. W.; Heo, G. S. \& Lee, G. H. - Anal. Sci., 13, p.257 (1997). http://dx.doi.org/10.2116/analsci.13. Supplement_257

13. Smith, P. B.; Pasztor, A. J.; McKelvy, M. L.; Meunier, D. M.; Froelicher, S. W. \& Wang, F. C. Y. - Anal. Chem., 71, p.61 (1999). http://dx.doi.org/10.1021/a1990004f

14. Blazsó, M. - J. Anal. Appl. Pyrolysis, 39, p.1 (1997). http:// dx.doi.org/10.1016/S0165-2370(96)00956-4

15. Alekseeva, K. V. - J. Anal. Appl. Pyrolysis, 2, p.19 (1980). http://dx.doi.org/10.1016/0165-2370(80)80042-8

16. Jiménez, A. \& Ruseckaite, R. A. - "Pyrolysis-GC/MS techniques for polymer characterization and degradation" in: Encyclopedia of Chromatography, cap. 298, Jack Cazes (ed.), Taylor \& Francis, Boca Raton (2005).

17. Bart, J. C. J. - "Additives in polymers: industrial analysis and applications", John Wiley \& Sons, Chichester (2005). http://dx.doi.org/10.1002/0470012064

18. Nunes, S. P.; Costa, R. A.; Barbosa, S. P.; Almeida, G. R. \& Galembeck, F. - IEEE Trans Electr Insul., 24, p.99 (1989). http://dx.doi.org/10.1109/14.19871

19. Matheson, M. J.; Wampler, T. P. \& Simonsick, W. J. - J. Anal. Appl. Pyrolysis, 29, p.129 (1994). http://dx.doi. org/10.1016/0165-2370(94)00791-8
20. Fernández-Berridi, M. J.; González, N.; Mugica, A. \& Bernicot, C. - Thermochim. Acta, 444, p.65 (2006). http:// dx.doi.org/10.1016/j.tca.2006.02.027

21. Sanches, N. B.; Diniz, M. F.; Reis, T. B.; Cassu, S. N. \& Dutra, R. C. L. - Polímeros, 16, p.211 (2006). http://dx.doi org/10.1590/S0104-14282006000300010

22. American Society for Testing and Materials - ASTM. - "D1566: standard terminology relating to rubber", ASTM, Philadelphia (2011).

23. American Society for Testing and Materials - ASTM. - "D3568: standard test methods for rubber. Evaluation of EPDM (Ethylene Propylene Diene Terpolymers) including mixtures with oil", ASTM, Philadelphia (2009).

24. Socrates, G. - "Infrared and raman characteristic group frequencies: tables and charts", Wiley \& Sons, Chichester (2001).

25. Welti, D. \& Stephany, R. - Appl. Spectrosc., 22, p.678 (1968). http://dx.doi.org/10.1366/000370268774384119

26. Young, P. R. - "Practical spectroscopy: the rapid interpretation of spectral data", Thomson Learning, Pacific Groove (2000).

27. Silverstein, R. M.; Webster, F. X. \& Kiemle, D. J. - "Spectrometric identification of organic compounds", John Wiley \& Sons, New York (2005)

28. BIO-RAD/SADTLER Reference Database. (2013) Disponível em: <https://scifinder.cas.org/>.

29. Šmejkal, F.; Č́íhová, A.; Popl, M. \& Novák, J. - Angew. Makromol. Chem., 88, p.135 (1980). http://dx.doi. org/10.1002/apmc.1980.050880111

30. National Institute of Standards and Technology - NIST. NIST Chemistry WebBook. (2013). Disponível em: <http:// webbook.nist.gov/chemistry/name-ser.html>.

31. Nieuwenhuizen, P. J.; Reedijk, J.; van Duin, M. \& McGill, W. J. - Rubber Chem. Technol., 70, p.368 (1997). http:// dx.doi.org/10.5254/1.3538436

32. Contini, G.; Castro, V.; Stranges, S.; Richter, R. \& Alagia M. - J. Phys. Chem. A, 106, p.2833 (2002). http://dx.doi. org/10.1021/jp013423b

33. Wu, F. L.; Hussein, W. M.; Ross, B. P. \& McGeary, R P. - Curr. Org. Chem., 16, p.1555 (2012). http://dx.doi. org/10.2174/138527212800840964

34. Mohamed, T. A.; Mustafa, A. M.; Zoghaib, W. M.; Afifi, M. S.; Farag, R. S. \& Badr, Y. - Theochem, 868, p.27 (2008). http://dx.doi.org/10.1016/j.theochem.2008.07.037

Received: 09/26/13

Revised: 02/12/14

Accepted: 03/13/14 